\title{
LAS COMPETENCIAS DE LOS SUBSECRETARIOS Y DIRECTORES GENERALES EN MATERIA DE PERSONAL
}

Por AURELIO ALONSO-CORTES CONCEJO

\section{Introducción}

\begin{abstract}
Como cuestión previa a la de fondo de este trabajo, es preciso puntualizar dos tipos de cuestiones, que se refieren a los funcionarios de los nuevos cuerpos generales creados por la vigente legislación de funcionarios y a la Administración militar.

La ponencia presentada por el profesor Guaita en la III Semana de Estudios sobre la Reforma Administrativa defendia la dependencia de los funcionarios de los cuerpos generales de la Presidencia del Gobierno, por ser el departamento más «administrativo», más general y menos técnico; por las facultades que la ley de Régimen Jurídico de la Administración del Estado (en adelante, LRJAE) le atribuye en materia de personal, y por las genéricas que posee respecto a los restantes ministerios, debido a su calidad de primus inter pares.
\end{abstract}


De la Vallina, en comunicación leida en la misma Semana, estima que no existe tal problema de dependencia si se tienen en cuenta los dos tipos de relación juridico-administrativa que unen al funcionario con la Administración. "Hasta ahora los funcionarios de los cuerpos generales mantienen su relación de servicio y orgánica con el Estado a través de un mismo departamento. De ahora en adelante, y a consecuencia de la unificación, dichas relaciones quedan claramente distinguidas, manteniéndose la relación de servicio con la Presidencia del Gobierno y la relación orgánica con el ministerio concreto donde el funcionario se encuentre destinado.»

Pues bien, nuestro estudio se refiere a las competencias de los subsecretarios y directores generales en el seno de la relación orgánica que une al funcionario con el departamento en el que lleva a cabo sus funciones.

Las peculiaridades de la Administración militar son, si cabe, más patentes en materia de personal. La importancia de este para la consecución de los fines de las fuerzas armadas y la trascendencia táctica de su distinto ordenamiento y organización hacen necesario el establecimiento de competencias coincidentes por razón de los sujetos sobre los que operan, asignadas a las subsecretarías u órgano equivalente y a los estados mayores. Asimismo, la importancia cualitativa y cuantitativa del factor humano impone la necesidad de contar con unas direcciones generales de personal para la gestión de los asuntos genéricos y comunes que se refieren al mismo. El presente trabajo ha de abordar tan sólo la problemática del tema escogido en la Administración civil.

\section{Criterios sobre distribución de competencias de personal entre subsecretarios y directores generales}

La LRJAE coloca a la cabeza de sus disposiciones las de distribución de competencias entre los distintos órganos de la Administración del Estado. Debido a su rango jurídico, son varias las normas posteriores que, siguiendo una técnica correcta, se remiten a ella cuando de deslindar atribuciones en materia de personal se trata; tal es el caso de la ley de Bases de Funcionarios Civiles del Estado $y$ de su texto articulado (en lo sucesivo, LF) (1).

Sin embargo, y como herencia de unas prácticas administrativas poco uniformes y de la indole política de las materias de adminis-

(1) Ley de Bases de 20 de fullo de 1963 y texto articulado aprobado por clecreto $315 / 1964$, de 7 de febrero. 
tración de personal, no aparecen claros ni se desprenden de aquel texto unos criterios generales de distribución de competencias en tales materias entre los subsecretarios y los directores generales.

La LRJAE acude al sistema de la enumeración no exhaustiva de las facultades de dichos órganos acompañada de una cláusula genérica de remisión a las disposiciones vigentes, añadiendo que «la competencia específica de los distintos órganos de los departamentos ministeriales se determinará en sus respectivos reglamentos orgánicos» (2).

Dicha técnica es tanto más imperfecta cuanto de un lado establece como facultad del subsecretario resolver todos los asuntos de personal, "salvo casos reservados a la decisión del ministro o de los directores generales», lo que nada aclara (3), y de otro regula, en el artículo 17, competencias coincidentes entre subsecretarios y directores generales en materia de ascensos, excedencias y jubilación que se acuerden de conformidad con facultades regladas.

El aludido mecanismo obliga a un difícil repaso de las disposiciones en vigor, tanto más penoso cuanto, por una parte faltan criterios que lo orienten $\mathrm{y}$, de otra, las normas generales, salvo rigurosas excepciones, siguen sin incluir la cláusula derogatoria impuesta por el artículo 129 de la ley de Procedimiento Administrativo, con lo que no existe seguridad respecto al derecho a considerar.

Además, al venir en la LRJAE determinadas algunas atribuciones por exclusión de las correspondientes a los ministros y directores generales - véase artículo 15, números 2 y 4-, es preciso conocer de antemano las corresponđientes a éstos, lo que no es nada fácil sin contar con unos previos principios, habida cuenta que dicha ley establece - como se verá-competencias coincidentes entre subsecretarios y directores generales. Para salir de esta petición de principio es necesario fijar los criterios doctrinales que permitan deslindar el correspondiente ámbito funcional.

El artículo 15.2 de la LRJAE parte del principio de que al subsecretario corresponde desempeñar la jefatura superior de todo el personal del departamento. Al excluir de la resolución del subsecretario los «casos reservados» a la decisión del ministro o de los directores generales, y sobre la base de que todo lo no excluido le está atribuido,

(2) Ver artículos 15.6., 16.6. y 20 de dicha ley.

(3) Artículo 15.2. El propio articulo 15, en su apartado 4, regula como una de las facultades del subsecretario la de "resolver los respectivos expedientes cuando no sea facultad privativa del ministro o de los directores generales". 
permite sostener de entrada que al subsecretario pertenecen todas las competencias que en las normas de personal no son asignadas a otros órganos concretos. La LF ofrece abundantes supuestos para la aplicación de dicho principio; asi debe entenderse que la remisión de antecedentes e informes solicitados por la Comisión Superior de Personal a un ministerio debe realizarse por la subsecretaría al no imponerse dicha obligación a otros órganos (4).

Veamos cuáles son los «casos reservados» a los ministros y a los directores generales para deducir por la vía de exclusión que establece el artículo 15, números 2 y 4 , de la LRJAE, las atribuciones del subsecretario.

Son facultades en materia de personal atribuidas directamente al ministro las de:

a) Nombrar y separar a las autoridades y funcionarios que no puedan considerarse «altos cargos» del departamento (5).

b) Destinar y ascender de acuerdo con facultades discrecionales.

c) Otorgar y proponer, en su caso, las recompensas que procedan (6).

d) Ejercer la facultad disciplinaria.

e) Cuantas facultades le atribuyan las disposiciones vigentes. Entre ellas, citaremos las reguladas en los artículos $6 .^{\circ}$ y 103 de la LF de autorizar la contratación de personal para la realización de estudios, proyectos, dictámenes y otras realizaciones, y la de designar funcionarios eventuales.

Son competencias del ministro, siempre que se refieran a personal:

a) El ejercicio de la iniciativa, dirección e inspección de los servicios del departamento y organismos adscritos.

b) La preparación y presentación al gobierno de proyectos de ley o decreto.

c) El ejercicio de la potestad reglamentaria.

d) Disponer de los gastos no reservados al Consejo de Ministros.

(4) Articulo 11 LF. Dicha atribución y obligación es consecuencia de la tradicional competencia del subsecretario en orden a mantener la comunicaclón del ministerio con otros organismos y entidades. Ver el artículo 15.5. LRJAE y el decreto de 8 de septiembre de 1962, que reorganiza la subsecretaria del Ministerio de Información y Turismo.

(5) A partir de la LF la separación del servicio no es, a nuestro entender, facultad del ministro, sino del proplo Gobierno, a propuesta del ministro y previa audiencia de la Comisión Superior de Personal (artículo 91.2.): en tal sentido ha de entenderse modificada la LRJAE.

(6) Es la aludida facultad tan privativa del ministro que es de las normalmente exceptuadas de celegación. (Véase orden de 20 de jullo de 1962, del Ministerio de Información y Turismo, apartado 3 . fl).] 
Es de notar que la propia LRJAE coloca el acento de la distinción entre las facultades del ministro, por un lado, $y$, por otro, de los subsecretarios y directores generales, en orden a ascensos y destinos en el carácter discrecional con que pueden conferirles los primeros $y$ en el reglado de las facultades de los segundos.

Ahora bien; si la LRJAE deja suficientemente claro el alcance de la competencia ministerial en asuntos de personal y, como consecuencia, delimita en parte, por exclusión, la competencia de los subsecretarios, no ofrece módulo alguno para deslindar las competenclas entre éstos y los directores generales.

La LRJAE tan sólo establece en los articulos 15 y 16 las competencias genéricas de ambas autoridades sin concretarse a las de personal, $y$ en el artículo 17 refiere las facultades coincidentes de las mismas en asuntos de «ascensos, destinos, excedencias, jubilaciones de los funcionarios públicos que se realicen de acuerdo con facultades regladas».

Ello hace necesario la fijación de un criterio funcional de distribución, aparte del ya apuntado de que el subsecretario ostenta todas las facultades en materia de personal no atribuidas especificamente a los directores generales $u$ otro órgano, de las que habrá, asimismo, que excepcionar aquellas competencias que, por ser inherentes a las administraciones o jefaturas de personal, son inmediatamente ejercidas por todas ellas.

$Y$ en este ámbito, un criterio funcional impone el que las dichas competencias coincidentes se ejerciten por el órgano bajo cuya dependencia inmediata se encuentre el personal de que se trata.

Aparte de los supuestos del articulo 17 de la LRJAE, son otros muchos los casos que denominamos de competencias coincidentes, que han de resolverse según dicho criterio funcional; ocurre, por ejemplo, respecto a la facultad de conceder permisos de hasta diez días de duración otorgada por igual por el artículo 70 de la LF a ambas autoridades, la cual sólo puede ejercitarse por cada una de ellas en relación a los funcionarios de sus respectivos organismos.

El anterior criterio no es del todo predicable de aquellas facultades que, aunque análogas, son ejercidas en un ámbito distinto. Acontece con el ejercicio de las respectivas atribuciones de vigilancia, control y establecimiento del régimen interior, ya que, mientras las competencias del director general no exceden o sobrepasan «las dependencias a su cargo», las del subsecretario van más allá, hasta 
alcanzar todos los «centros, dependencias y organismos afectos al departamento» (7).

Según el criterio funcional que hemos sentado, les pertenecen las facultades de propuesta de resolución respecto a los asuntos de personal de la competencia del ministro y cuya tramitación corresponda al organismo de su jefatura, y en tal sentido debe considerarse aplicable al subsecretario el número 3 del artículo 16 de la LRJAE.

Establecido un nuevo criterio de distribución de competencias, no estará de más extraer de las «leyes y reglamentos» a que se refiere el artículo últimamente citado algunas de las atribuciones de los directores generales. En el texto articulado de la LF hallamos las siguientes facultades.

a) Ordenar la incoación de expedientes disciplinarios por faltas graves y muy graves (artículo 92.1).

b) Corregir las faltas leves imponiendo la pérdida de uno a cuatro días de remuneración o el apercibimiento del funcionario (artículo 91.4).

c) Ordenar la formación de las correspondientes plantillas del centro (artículo 52.3) (8).

d) Conceder licencias al personal cuando asi se disponga reglamentariarnente (artículo 75).

Es competencia de los directores generales, impuesta por normas reglamentarlas, la dirección de los resúmenes de plantillas parciales de personal en la forma prevista por el decreto $865 / 1964$, de 9 de abril.

Sin embargo, de poca utilidad servirá la anterior enumeración y la de las facultades ministeriales en orden a obtener por exclusión las pertenecientes a los subsecretarios, según la técnica seguida por el artículo 15, apartados 2 y 4 de la LRJAE, ya que toda enumeración será slempre imperfecta $y$, por lo mismo, el sistema de deslinde, por exclusión que de ella resulte. Lo más efectivo será disponer de unos criterios o principios de delimitación como los ya apuntados.

En cualquier caso, parece conveniente formar una relación o cuadro de atribuciones que corresponden a los subsecretarios, según la LF vigente. $Y$ éstas son:

(7) Compárense los artículos 15.3., y 16.1. de la LRJAE.

(8) Desde siempre ha sldo facultad de las direcclones .generales la le propuesta en materia de plantilla, cuya aprobación incumbía al ministro. En el sistema de la vigente LF, éste, a nuestro entender, ha sido reformado Respecto al sistema anterior, ver la orden de 31 de mayo de 1952 dictada por el Ministerio de Agricultura. 
a) La adscripción de los funcionarios del departamento a una plaza determinada dentro de los servicios del mismo en cada localidad (artículo 55).

b) Conceder autorización a los funcionarios de los cuerpos generales de servicio en el departamento para asistir a los cursos de perfeccionamiento (artículo 33).

c) Determinar la urgencia para provisión con carácter forzoso de las vacantes declaradas desiertas en el concurso de provisión correspondiente (articulo 61).

d) Autorizar las permutas entre funcionarios del departamento e informar las que haya de autorizar el vicepresidente de la Comisión Superior de Personal (artículo 62).

e) La concesión de licencias al personal, salvo que reglamentariamente se asigne al director general (articulo 75 ).

f) La resolución de expedientes de incompatibilidades para la autorización del ejercicio de otra profesión por un funcionario (artículo 83.1).

Por su parte, las normas reglamentarias dictadas para el desarrollo de la LF les confieren diversas facultades, como es la de dirigir la confección de las hojas de servicio correspondientes a los funcionarios de los cuerpos especiales que dependen de la subsecretaria y que quedan en la correspondiente sección de personal. En materia de clasificación de puestos de trabajo, ejercen la presidencia de la Junta de Clasificación del Ministerio, dictando las órdenes oportunas para el debido cumplimiento del programa de descripción y clasificación, y aprueban las propuestas de clasificación que han de ser remitidas a la Presidencia del Gobierno (9).

La delimitación de competencias de que se ha tratado es tanto más importante cuanto la LRJAE dispone en su articulo 36.4 que ponen fin a la via gubernativa las resoluciones de los subsecretarios y directores generales «relativas al personal», texto que ha de ser entendido en el sentido de que dicho término se produce cuando cada una de dichas autoridades resuelvan en materias de su competencia propia o delegada, ya que, en otro caso, procederá siempre la alzada ante la autoridad superior.

Es principio admitido que las facultades que a los directores generales otorga el artículo aludido encuentran un limite en lo que es atribución exclusiva del ministro o del subsecretario.

$\mathrm{X}$ ello porque el propio texto establece en el apartado 5 que ponen

(9) Ver artículo $60^{\circ}$ del decreto $864 / 1964$, de 9 de abril, y el decreto 865 de la misma fecha. 
fin a la via gubernativa las resoluciones de cualquier autoridad cuando asi lo establezca una disposición legal o reglamentaria, lo que ha inducido a la jurisprudencia a afirmar que, «si bien es cierto que con arreglo al número $4 .^{\circ}$ de dicho artículo 36 ponen fin a la via administrativa las resoluciones de los subsecretarios y directores generales relativas al personal, ello debe entenderse cuando no se disponga lo contrario en una disposición legal o reglamentaria a que se refiere el número $5^{\circ}$ del mismo articulo» (sentencia de 16 de octubre de 1963).

Al frente de tales excepciones se encuentran las atribuciones exclusivas de los ministros conferidas por los apartados 5 y 6 del artículo 14 de la LRJAE, que atribuye a los titulares de los departamentos ministeriales el nombramiento y separación de sus funcionarios y el ejercicio de facultades disciplinarias y de recompensa.

\section{La competencia delegada en materias de personal}

Si bien es cierto que en los anteriores casos las resoluciones de los subsecretarios y directores generales, adoptadas iure proprio, no causan estado, no lo es menos que pueden ser definitivas cuando se ejercitan competencias delegadas por imperativo del aludido articulo 36 en su apartado 3 , a tenor del cual ponen también fin a la vía gubernativa las resoluciones «de las autoridades inferiores en los casos que resuelvan por delegación de un ministro o de otro órgano cuyas resoluciones pongan fin a la via administrativa».

Sin ánimo de extendernos en materias de delegación de atribuciones relativas a personal, es preciso decir que la anterior norma ha sido tradicional en nuestro Derecho. Asi, por no citar más que una, la orden del Ministerio de Agricultura de 16 de agosto de 1946 estableció, en su artículo $5 .^{\circ}$, que «las resoluciones adoptadas por la subsecretaria, en virtud de la delegación acordada, se entenderán como defínitivas y apurarán la via gubernativa».

La LRJAE establece el principio general de que las competencias administrativas son delegables en los órganos inferiores. Concretamente, las competencias de los ministros, en los subsecretarios, y las de éstos, en los directores generales, con las excepciones establecidas en los apartados $a$ ) al $e$ ) del artículo 22 de la propia ley.

Por la indole del presente trabajo, nos interesan los problemas de delegación de atribuciones en asuntos de personal sólo en cuanto se relacionan con las mismas competencias. 
La distinción entre ambos tipos de competencia, originales y delegadas, aparece en múltiples disposiciones, algunas de ellas no menos interesantes por carecer de vigencia (10).

Al no existir antes de la LRJAE una norma de rango suficiente que uniformara materia tan importante como la de las facultades de delegación, cada departamento obraba en este punto según sus necesidades, partiendo todos ellos del propósito, logrado con más o menos fortuna, de descargar a la jefatura de funciones que pudieran desarrollar órganos inferiores en inmediación con los asuntos, y de imprimir al procedimiento los principios de economía, celeridad y eficacia.

Ello originó las más amplias delegaciones del ministro en los subsecretarios y directores generales, ya genéricas respecto de toda clase de asuntos, ya especificas en materias de personal (11).

Hay que afirmar que a partir de la LRJAE no parecen licitas las delegaciones genéricas y en bloque, ya que a la delegación ha de serle previa la existencia de la facultad, y éstas vienen taxativamente recogidas en dicho texto legal y en las leyes y disposiciones orgánicas.

Por otra parte, en el pasado, numerosas órdenes ministeriales de delegación incluyeron cuantos asuntos requerian para su resolución la firma del ministro, tales como corridas de escalas, ascensos, nombramlentos, excedencias, licencias, traslados, etc. Ello es incorrecto a partir de la LRJAE, habida cuenta que al dictarse la resolucion en tales asuntos, de acuerdo con facultades regladas, se trata ya de materias de la competencia propia, que no delegada, de los subsecretarios y jefes de los centros directivos.

Al haber realizado la LRJAE un primer deslinde de atribuciones entre los órganos superiores de los departamentos, la delegación se realiza en relación a facultades concretas del organo delegante. $Y$ asi llega a ser común la formula de delegar en el subsecretario, no todos los asuntos de personal, sino las atribuciones que se consignan en los números 4,5 y 6 -inciso segundo-, 7 y 8 -inciso primero-, 11 y 12 del artículo 14 de la LRJAE; suele exceptuarse la facultad de concesión y propuesta de recompensas, que ha sido atribución clásica de los ministros.

(10) A tenor del artículo 2." del decreto de 6 de abril de 1938, referente al Ministerio de Agricultura "La subsecretaría ejercerá las funciones que le son propias y aquellas que por delegación le fueron conferidas».

(11) Ejemplo de delegaciones genéricas to constituye la orden del Ministerio de Información y Turismo de 4 de agosto de 1951, y de delegaciones especificas en materias de personal la del mismo departamento de 21 de octubre de 1958. 
Es de notar que la materia de nombramiento de altos cargos no es delegable en cuanto, a tenor del artículo 10 de la ley tantas veces citada, deben ser designados por decreto, por lo que están exceptuados de delegación. Sin embargo, todo dependerá del alcance que quiera darse al concepto de «alto cargo».

$Y$, en fin, no haỳ ni que añadir que, en buenos términos juridicos, las facultades ejercidas por los directores generales no podrán proceder de competencias delegadas a su vez por los ministros en los subsecretarios, ya que lo impide el principio comúnmente aceptado de que no pueden delegarse las atribuciones que han sido obtenidas por delegación. 
DA-1965, núm. 90. AURELIO ALONSO-CORTÉS CONCEJO. Las competencias de los subsecretarios 